\title{
Influence of dihydroxybenzenes on paracetamol and ciprofloxacin degradation and iron(III) reduction in Fenton processes
}

\author{
Beatriz Costa e Silva $^{1}$ • João Angelo de Lima Perini ${ }^{1}$ Raquel F. Pupo Nogueira ${ }^{1}$
}

Received: 21 December 2015 / Accepted: 1 March 2016/Published online: 14 March 2016

(C) Springer-Verlag Berlin Heidelberg 2016

\begin{abstract}
The degradation of paracetamol (PCT) and ciprofloxacin (CIP) was compared in relation to the generation of dihydroxylated products, $\mathrm{Fe}(\mathrm{III})$ reduction and reaction rate in the presence of dihydroxybenzene (DHB) compounds, or under irradiation with free iron $\left(\mathrm{Fe}^{3+}\right)$ or citrate complex (Fecit) in Fenton or photo-Fenton process. The formation of hydroquinone (HQ) was observed only during PCT degradation in the dark, which increased drastically the rate of PCT degradation, since $\mathrm{HQ}$ formed was able to reduce $\mathrm{Fe}^{3+}$ and contributed to PCT degradation efficiency. When HQ was initially added, PCT and CIP degradation rate in the dark was much higher in comparison to the absence of $\mathrm{HQ}$, due to the higher and faster formation of $\mathrm{Fe}^{2+}$ at the beginning of reaction. In the absence of HQ, no CIP degradation was observed; however, when HQ was added after $30 \mathrm{~min}$, the degradation rate increased drastically. Ten PCT hydroxylated intermediates were identified in the absence of HQ, which could contribute for Fe(III) reduction and consequently to the degradation in a similar way as HQ. During CIP degradation, only one product of hydroxyl radical attack on benzene ring and substitution of the fluorine atom was identified when HQ was added to the reaction medium.
\end{abstract}

Responsible editor: Philippe Garrigues

Electronic supplementary material The online version of this article (doi:10.1007/s11356-016-6402-1) contains supplementary material, which is available to authorized users.

Raquel F. Pupo Nogueira

nogueira@iq.unesp.br

1 Department of Analytical Chemistry, Institute of Chemistry, UNESP - Univ Estadual Paulista, PO Box 355, 14800-060 Araraquara, SP, Brazil
Keywords Hydroquinone · Catechol · Pharmaceuticals Intermediates $\cdot$ Iron cycling $\cdot \mathrm{LC}-\mathrm{MS} / \mathrm{MS}$

\section{Introduction}

Advanced oxidation processes based on Fenton reaction have been reported as particularly efficient technologies for the removal of persistent organics like pesticides, dyes, pharmaceuticals, and phenolic compounds (Pignatello et al. 2006; Wang and $\mathrm{Xu}$ 2012). Pharmaceuticals are detected in aqueous environment at low levels, $\mathrm{ng} \mathrm{L}^{-1}$ to $\mu \mathrm{g} \mathrm{L}^{-1}$, and are not completely eliminated in conventional wastewater treatment (Pomati et al. 2006; Rúa-Gómez and Püttmann 2013).

In Fenton process, ${ }^{\circ} \mathrm{OH}$ is generated during $\mathrm{H}_{2} \mathrm{O}_{2}$ decomposition with free, complexed, or insoluble iron species, presenting ability to oxidize a wide spectrum of organic contaminants as pharmaceuticals to end products such as $\mathrm{CO}_{2}, \mathrm{H}_{2} \mathrm{O}$, and inorganic ions with a low selectivity (Pignatello 1992). Other oxidizing species have also been reported to contribute to the degradation of organic compounds like ferryl ion $\left(\mathrm{FeO}^{2+}\right.$ ) (Minero et al. 2013). However, its role on degradation mechanism is still questioned (Pang et al. 2011).

The photo-Fenton process is a typically radiation-enhanced Fenton reaction resulting in mineralization of recalcitrant organic compounds. In aqueous solutions and at correct $\mathrm{pH}$, $\mathrm{Fe}^{3+}$ acts as light-absorbing species producing extra ${ }^{\circ} \mathrm{OH}$ while the $\mathrm{Fe}^{2+}$ is formed (Eq. 1) (Pignatello 1992).

$\mathrm{Fe}(\mathrm{OH})^{2+}+\mathrm{hv} \rightarrow \mathrm{Fe}^{2+}+\mathrm{OH}+\mathrm{OH}^{-}$

Ferric complexes of organic ligands as oxalate, citrate, or tartrate are used in photo-Fenton process to increase efficiency of Fe(III) reduction due to an effective ligand to metal charge transfer and also the shift of absorption toward longer 
wavelengths in relation to aqua complexes (Abrahamson et al. 1994; Safarzadeh-Amiri et al. 1996; Nogueira et al. 2005a; Wang et al. 2009).

The presence of aromatic species as hydroxy, nitro, and hydroxynitro benzoic acid derivatives has been studied to assess their influence on Fenton reactions due to their ability to reduce $\mathrm{Fe}(\mathrm{III})$, a limiting step on Fenton process, and thus produce ${ }^{\circ} \mathrm{OH}$ during $\mathrm{H}_{2} \mathrm{O}_{2}$ decomposition (Chen and Pignatello 1997; Aguiar et al. 2007; Haddou et al. 2010). The role of HQ in the reduction of Fe(III) during the degradation of organic compounds in Fenton-like conditions has been also reported (Chen et al. 2002; Devi et al. 2011; Minella et al. 2014). The effect on degradation may vary depending upon the position of the substituents and formation of intermediates that can improve or decrease Fe(III) reduction (Nichela et al. 2010). It was previously observed that HQ and catechol (CAT) accelerated significantly the phenol degradation changing drastically the reaction kinetics after their generation as intermediate in the dark (Silva and Nogueira 2016).

Some authors have reported that hydroxylated compounds as HQ were formed as intermediate of paracetamol (PCT) degradation (Andreozzi et al. 2003; Moctezuma et al. 2012; Laurentiis et al. 2014) due to 'OH attack on benzene ring. However, its effect on reaction rate was only considered by Trovó et al. (2012) who reported higher efficiency of PCT degradation when mediated by $\mathrm{FeSO}_{4}$ in comparison to ferrioxalate (FeOx) and proposed that hydroxylated intermediates could catalyze $\mathrm{Fe}(\mathrm{III})$ reduction.

Considering that PCT contains a phenolic group in its structure, the purpose of this work is to compare its degradation with ciprofloxacin (CIP), a widely used fluoroquinolone pharmaceutical presenting no phenolic group. The comparison was based on generation of hydroxylated products, on $\mathrm{Fe}(\mathrm{III})$ reduction, and on degradation rate. Furthermore, the effect of HQ addition to PCT and CIP solution during degradation was evaluated in the dark and under irradiation and in the presence and absence of citrate as iron complexing agent. The main degradation intermediates were identified using liquid chromatography coupled to mass spectrometry (LC-MS/MS).

\section{Experimental}

\section{Reagents}

Paracetamol (100.29\%) $\left(\mathrm{C}_{8} \mathrm{H}_{9} \mathrm{NO}_{2} ; \mathrm{MW}=151.15 \mathrm{~g} \mathrm{~mol}^{-1}\right)$ and ciprofloxacin (99\%) $\left(\mathrm{C}_{17} \mathrm{H}_{18} \mathrm{FN}_{3} \mathrm{O}_{3} \cdot \mathrm{HCl} \cdot \mathrm{H}_{2} \mathrm{O}\right.$; $\mathrm{MW}=385.82 \mathrm{~g} \mathrm{~mol}^{-1}$ ) were obtained from Pharma Nostra (São Paulo, Brazil) and were used to prepare aqueous $0.4 \mathrm{mmol} \mathrm{L}{ }^{-1}$ solution. $\mathrm{Fe}\left(\mathrm{NO}_{3}\right)_{3} \cdot 9 \mathrm{H}_{2} \mathrm{O}$ (Mallinkrodt, Paris,
KY, USA) and $\mathrm{FeSO}_{4} \cdot 7 \mathrm{H}_{2} \mathrm{O}$ (Fmaia, Cotia, Brazil) were used to prepare aqueous $0.25 \mathrm{~mol} \mathrm{~L}^{-1}$ iron stock solution. Citric acid (Synth, São Paulo, Brazil) was used as an iron ligand. Hydroquinone (CAAL, São Paulo, Brazil) and catechol (Sigma-Aldrich, St. Louis, MO, USA) were used on PCT and CIP degradation. $\mathrm{H}_{2} \mathrm{O}_{2} 30 \%(w / w)$ (Synth, São Paulo, Brazil) was used as received after standardization. Bovine liver catalase from Sigma-Aldrich (St. Louis, MO, USA) was used for residual hydrogen peroxide consumption. Ammonium metavanadate (Vetec, Rio de Janeiro, Brazil) $0.06 \mathrm{~mol} \mathrm{~L}^{-1}$ was prepared in $0.36 \mathrm{~mol} \mathrm{~L}^{-1} \mathrm{H}_{2} \mathrm{SO}_{4}$ (Fmaia, Cotia, Brazil) and used for hydrogen peroxide determination. Acetonitrile (J. T. Baker, Xalostoc, Mexico), formic acid (J. T. Baker, Xalostoc, Mexico), and ultrapure water (DG 500UF, Gehaka, São Paulo, Brazil) were used for HPLC analysis.

\section{Degradation procedures}

Experiments under irradiation or in the dark were carried out in an up-flow reactor previously described (Nogueira and Guimarães 2000). The irradiation source was a $15-\mathrm{W}$ blacklight lamp with maximum emission at 365 and $410 \mathrm{~nm}$. When irradiation was employed, the lamp was only switched on once the reactor was completely filled and the time started to be monitored. The $\mathrm{pH}$ of PCT or CIP solution was firstly adjusted to 2.5 using a $\mathrm{pH}$ meter (1100 series, Oakton, Vernon Hills, IL, USA) with the addition of $1.0 \mathrm{~mol} \mathrm{~L}^{-1}$ $\mathrm{H}_{2} \mathrm{SO}_{4}$ solution. After $\mathrm{pH}$ adjustment, the iron salt was added to result in a $0.10 \mathrm{mmol} \mathrm{L}^{-1}$ concentration. Iron citrate complex (Fecit) was prepared in situ by the addition of citric acid to iron nitrate solution at 1:1 iron to ligand molar ratio. Appropriate volume of $\mathrm{H}_{2} \mathrm{O}_{2}$ was then added to result in $2.5 \mathrm{mmol} \mathrm{L}^{-1}$ concentration while magnetically stirred, and the solution was then immediately pumped into the reactor. The irradiated volume of the reactor was $280 \mathrm{~mL}$, and a total volume of $500 \mathrm{~mL}$ of $0.4 \mathrm{mmol} \mathrm{L}^{-1}$ PCT or CIP solution was recirculated at $80 \mathrm{~mL} \mathrm{~min}^{-1}$ flow rate using a peristaltic pump (Masterflex 7518-12, Vernon Hills, IL, USA). CAT was added at $0.10 \mathrm{mmol} \mathrm{L}^{-1}$, and $\mathrm{HQ}$ was added at concentrations ranging from 0.05 to $0.15 \mathrm{mmol} \mathrm{L}^{-1}$ to evaluate their effect on iron reduction, peroxide consumption, and on PCT and CIP degradation.

\section{Chemical analysis}

The concentration of PCT, CIP, CAT, and HQ during the experiments was determined using reversed-phase high-performance liquid chromatography (HPLC; 20AT Prominence, Shimadzu, Kyoto, Japan) coupled to a diode array detector (DAD) (SPD-M20A). The injection volume was $20 \mu \mathrm{L}$, and a C-18 column (Gemini $5 \times 150 \times 4.6 \mathrm{~mm}$ Phenomenex, Torrance, CA, USA) was used with a mixture of acetonitrile: formic acid $0.1 \%$ as mobile phase at $0.4 \mathrm{~mL} \mathrm{~min}^{-1}$ flow rate 
and isocratic mode. Samples from PCT degradation were eluted with 15:85 acetonitrile:formic acid 0.1\%, while samples from CIP degradation were eluted with 20:80. Under these conditions, retention times of PCT, CAT, and HQ were 7.9, 13.0, and $7.2 \mathrm{~min}$ detected at 242, 276, and $289 \mathrm{~nm}$ wavelength, respectively, while retention times of CIP and HQ were 5.2 and $6.4 \mathrm{~min}$ detected at 280 and $289 \mathrm{~nm}$ wavelength, respectively. Before HPLC analysis, $35 \mu \mathrm{L}$ of catalase solution $\left(0.1 \mathrm{~g} \mathrm{~L}^{-1}\right)$ was added to $5 \mathrm{~mL}$ aqueous sample after $\mathrm{pH}$ adjustment to 6-7 under magnetic stirring. This procedure was adopted to interrupt the Fenton reaction by the decomposition of residual $\mathrm{H}_{2} \mathrm{O}_{2}$ and iron precipitation (Malato et al. 2002). The samples were then filtered through $0.45 \mu \mathrm{m}$ polyvinylidene fluoride membrane (Millipore, Bedford, MA, USA) before HPLC analysis.

Mineralization of organic matter during PCT and CIP degradation was evaluated by measuring the decay of total organic carbon concentration (TOC) using a TOC analyzer (TOC5000A-Shimadzu, Kyoto, Japan) immediately after the sample withdrawal without previous treatment.

The residual hydrogen peroxide concentration was determined spectrophotometrically (Shimadzu UV mini-1240, Shimadzu, Kyoto, Japan) by measuring the absorption at $450 \mathrm{~nm}$ after reaction with ammonium metavanadate (Nogueira et al. 2005b). The concentration of ferrous ions generated was measured using the spectrophotometric method employing 1,10-phenanthroline, with maximum absorption at 510 nm (UV mini-1240, Shimadzu, Kyoto, Japan) (Fortune and Mellon 1938).

Solid phase extractions were carried out for LC-MS/ MS analysis. Sep-Pak-C18 (360 mg) and Oasis HLB (60 mg) cartridges (Waters, Milford, MA, USA) were used for PCT and CIP determinations, respectively. SepPak-C18 cartridges were previously conditioned with $5 \mathrm{~mL}$ methanol followed by $5 \mathrm{~mL}$ water. Then $5 \mathrm{~mL}$ sample was percolated through the cartridge and recovered with $5 \mathrm{~mL}$ methanol. In the case of CIP, Oasis HLB cartridges were used after conditioning with $1 \mathrm{~mL}$ methanol followed by $1 \mathrm{~mL}$ water. Then $1 \mathrm{~mL}$ of sample was percolated through the cartridge and recovered with $1 \mathrm{~mL}$ methanol/formic acid 0.1\% (50:50) solution.

LC-MS/MS analysis was performed in a liquid chromatograph (1200 Agilent Technologies, Santa Clara, CA, USA) coupled to a 3200 QTRAP Mass Spectrometer (Linear Ion Trap Quadrupole, AB Sciex Instruments, Framingham, MA, USA) operating in a positive and negative mode and TurbolonSpray ionization. Fullscan and MS/MS experiments were carried out using the following parameters: curtain gas, $103 \mathrm{kPa}$; ion spray, $5500 \mathrm{~V}$; gas $1,310 \mathrm{kPa}$; gas 2, $276 \mathrm{kPa}$; temperature, $600{ }^{\circ} \mathrm{C}$, declustering potential, $36 \mathrm{~V}$; entrance potential, $4 \mathrm{~V}$, and interface heater, ON. The same chromatographic conditions were used as previously described.

\section{Results and discussion}

\section{Effect of DHB on PCT degradation}

Control experiments under only irradiation or in the presence of only $\mathrm{Fe}^{3+}$ showed no decrease of PCT concentration, while irradiation in the presence of $\mathrm{Fe}^{3+}$ resulted in $7 \%$ PCT oxidation with no mineralization after 90 min due to electron transfer from water to iron reducing $\mathrm{Fe}^{3+}$ and generating ${ }^{\circ} \mathrm{OH}$ that oxidizes PCT (Eq. 1). The Fecit complex was used as an iron source to compare the effect of HQ on the reduction of Fe(III) when presented as free or complexed iron.

In the absence of DHBs, a lag phase is observed in the first 20 min resulting in a similar initial degradation rate (calculated by the tangent of the initial linear portion of the curve of concentration as a function of reaction time) of PCT in the presence of either $\mathrm{Fe}\left(\mathrm{NO}_{3}\right)_{3}$ or Fecit, under irradiation, 0.042 and $0.064 \mathrm{mmol} \mathrm{L}^{-1} \mathrm{~min}^{-1}$, respectively, higher than in the dark, $0.013 \mathrm{mmol} \mathrm{L}^{-1} \mathrm{~min}^{-1}$ (Fig. 1a). However, degradation rate in the dark started to increase after $20 \mathrm{~min}$, reaching $0.019 \mathrm{mmol} \mathrm{L}^{-1} \mathrm{~min}^{-1}$, about 1.5 times higher, leading to more than $99 \%$ PCT degradation after $60 \mathrm{~min}$, the same as under irradiation.

The increase of PCT degradation rate in the dark with $\mathrm{Fe}\left(\mathrm{NO}_{3}\right)_{3}$ after $20 \mathrm{~min}$ is probably related to the formation of HQ (Fig. 1d), which is able to reduce Fe(III) to Fe(II) that decomposes $\mathrm{H}_{2} \mathrm{O}_{2}$ forming ${ }^{\circ} \mathrm{OH}$. Generation of DHB intermediates as HQ was previously observed during PCT and phenol Fenton degradation, which may influence reaction rate (Trovó et al. 2012; Moctezuma et al. 2012; Silva and Nogueira 2016).

To confirm that HQ was formed and not CAT, LC-MS experiments were carried out. Since both have the same molar weight, optimizations of fragment ion and ionization experiments were performed using direct infusion of each DHB standard. After obtaining all optimized conditions for HQ and CAT, selected reaction monitoring (SRM) analysis was carried out due to the high sensitivity. Two transitions (precursor ion $>$ fragment ion), usually selected through their intensity, were monitored for both HQ and CAT to confirm their presence. The transitions used were as follows: HQ 109>45 and 109>79 and CAT 109>91 and 109>81. The results indicated that only HQ was formed as PCT degradation product, since transitions of CAT were not observed (Fig. SM1).

When CAT and HQ were initially added to PCT solution in the dark, PCT degradation rate was significantly increased following pseudo first-order kinetics (Table 1). As a result, over $96 \%$ PCT degradation was observed in the presence of DHBs after $30 \mathrm{~min}$. The increase of PCT degradation rate in relation to the absence of DHBs confirms their catalytic effect on PCT degradation. Furthermore, higher PCT degradation rate was observed in the presence of DHBs than in the presence of irradiation with free $\mathrm{Fe}^{3+}$ or Fecit complex, indicating their higher contribution on $\mathrm{Fe}(\mathrm{III})$ reduction than irradiation. 
Fig. 1 Influence of CAT and HQ on (a) oxidation, (b)

mineralization of PCT, (c) $\mathrm{H}_{2} \mathrm{O}_{2}$ consumption, and (d) DHB concentration. Initial conditions: $\mathrm{C}_{\mathrm{PCT}}=0.4 \mathrm{mmol} \mathrm{L}^{-1}$;

$\mathrm{C}_{\mathrm{Fe} 3+}=0.1 \mathrm{mmol} \mathrm{L}^{-1}$;

$\mathrm{C}_{\mathrm{H} 2 \mathrm{O} 2}=2.5 \mathrm{mmol} \mathrm{L}^{-1} ; \mathrm{pH} 2.5$;

$\mathrm{Fe}^{3+} /$ dark; $\nabla \mathrm{Fe}^{3+} / \mathrm{UV} ; \boldsymbol{\Delta}$ Fecit

complex/UV; $\mathrm{Fe}^{3+}+$

$0.10 \mathrm{mmol} \mathrm{L}{ }^{-1} \mathrm{CAT} /$ dark; $\angle \mathrm{Fe}^{3+}$

$+0.15 \mathrm{mmol} \mathrm{L}^{-1} \mathrm{HQ} /$ dark;

$\mathrm{Fe}^{3+}+0.10 \mathrm{mmol} \mathrm{L}^{-1}$

$\mathrm{HQ} /$ dark; $\mathrm{Fe}^{3+} /$ dark;

$\mathrm{Fe}^{3+}+0.05 \mathrm{mmol} \mathrm{L}^{-1} \mathrm{HQ} /$ dark a

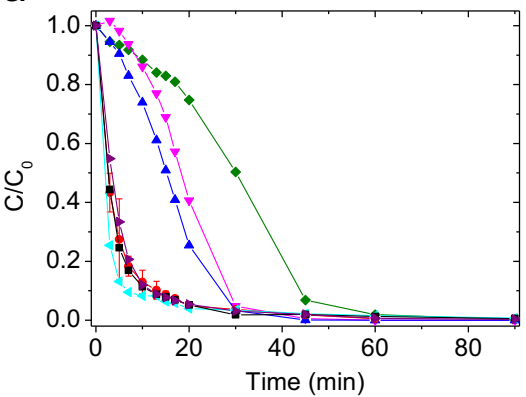

C

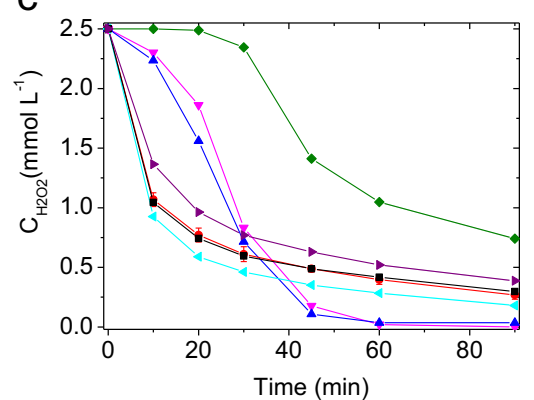

b

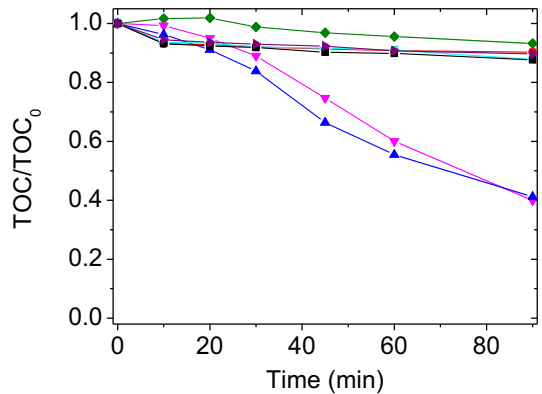

d

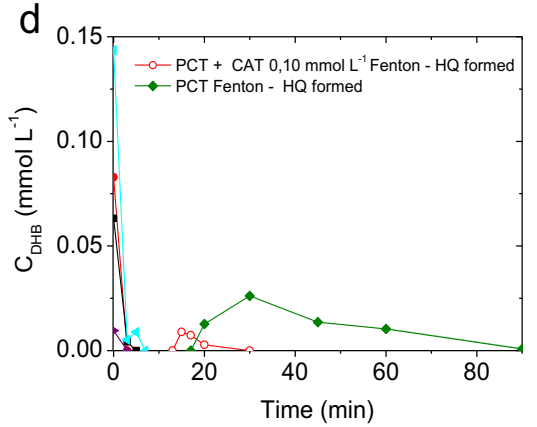

However, this effect was restricted to the beginning of the reaction since after 7 min DHBs were also degraded and concentration in solution decreased to levels below the detection limit, 8.6 and $1.1 \mu \mathrm{mol} \mathrm{L}^{-1}$ for HQ and CAT, respectively (Fig. 1d).

In relation to TOC removal, irradiation had a very strong positive effect independent of free $\left(\mathrm{Fe}^{3+}\right)$ or complexed iron (Fecit) achieving $59 \%$ TOC removal after 90 min (Fig. 1b). On the other hand, although the presence of HQ and CAT increased significantly the PCT degradation in the dark, TOC removal achieved only $7 \%$ after $10 \mathrm{~min}$ and $12 \%$ after 90 min probably due to the total conversion of these compounds after $7 \mathrm{~min}$.

Low $\mathrm{H}_{2} \mathrm{O}_{2}$ consumption (1\%) was observed during PCT degradation in the dark after $20 \mathrm{~min}$ in the absence of DHB with $\mathrm{Fe}^{3+}$. However, when HQ started to be detected, the consumption of $\mathrm{H}_{2} \mathrm{O}_{2}$ increased considerably suggesting that $\mathrm{HQ}$ contributed to $\mathrm{Fe}(\mathrm{III})$ reduction which decomposed $70 \%$ of $\mathrm{H}_{2} \mathrm{O}_{2}$ after 90 min (Fig. 1c). However, under irradiation up to $96 \%, \mathrm{H}_{2} \mathrm{O}_{2}$ was

Table 1 Pseudo firstorder rate constants $(k)$ for PCT degradation in the presence of $\mathrm{Fe}^{3+}$ in the dark

\begin{tabular}{ll}
\hline Solution & $k\left(\mathrm{~min}^{-1}\right)$ \\
\hline $0.10 \mathrm{mmol} \mathrm{L}^{-1} \mathrm{CAT}$ & 0.22 \\
$0.05 \mathrm{mmol} \mathrm{L}$ & $\mathrm{HQ}$ \\
$0.10 \mathrm{mmol} \mathrm{L}$ & 0.22 \\
$0.15 \mathrm{mmol} \mathrm{L}$ & 0.26 \\
\hline
\end{tabular}

Initial conditions: $\mathrm{C}_{\mathrm{PCT}}=0.4 \mathrm{mmol} \mathrm{L}^{-1}$; $\mathrm{C}_{\mathrm{Fe} 3+}=0.1 \mathrm{mmol} \mathrm{L}^{-1}$; $\mathrm{C}_{\mathrm{H} 2 \mathrm{O} 2}=2.5 \mathrm{mmol} \mathrm{L}^{-1} ; \mathrm{pH} 2.5$ decomposed after 45 min independent of free or complexed iron, much higher consumption than in the dark due to the continuous reduction of $\mathrm{Fe}(\mathrm{III})$. In this case, HQ and CAT were not detected in reaction medium indicating that iron reduction was mainly promoted by irradiation. When DHBs were added to the reaction medium, the consumption of $\mathrm{H}_{2} \mathrm{O}_{2}$ between 0 and 20 min was even higher than under irradiation resulting in significant iron reduction and $\mathrm{H}_{2} \mathrm{O}_{2}$ decomposition.

Measurements of $\mathrm{Fe}^{2+}$ concentration were carried out during PCT reaction to compare the effect of irradiation of Fecit complex with CAT and HQ on Fe(III) reduction (Fig. 2). Experiments were carried out in the absence of $\mathrm{H}_{2} \mathrm{O}_{2}$ to avoid $\mathrm{Fe}^{2+}$ oxidation. It was observed that in the

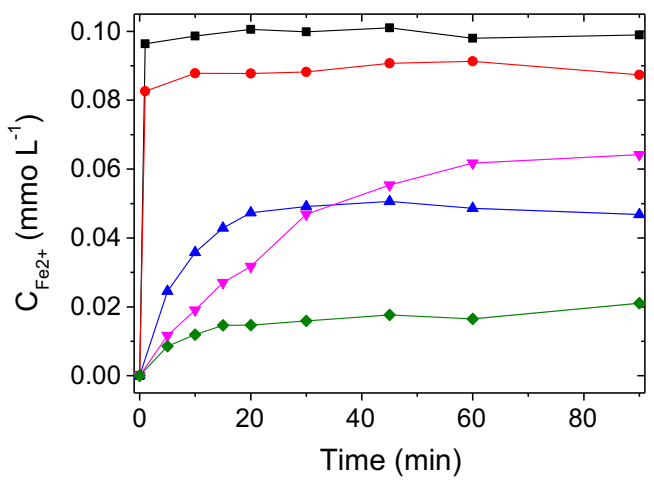

Fig. 2 Generation of $\mathrm{Fe}(\mathrm{II})$ during PCT reaction in the absence of $\mathrm{H}_{2} \mathrm{O}_{2}$ under different conditions: in the presence or absence of CAT and HQ, in the dark or under irradiation, with $\mathrm{Fe}^{3+}\left(\mathrm{Fe}\left(\mathrm{NO}_{3}\right)_{3}\right)$ or Fecit. Initial conditions: $\mathrm{C}_{\mathrm{PCT}}=0.4 \mathrm{mmol} \mathrm{L}{ }^{-1} ; \mathrm{C}_{\mathrm{Fe} 3+}=0.1 \mathrm{mmol} \mathrm{L}^{-1}$; $\mathrm{C}_{\mathrm{HQ}}=\mathrm{C}_{\mathrm{CAT}}=0.1 \mathrm{mmol} \mathrm{L}{ }^{-1} ; \mathrm{pH} 2.5 ; \nabla \mathrm{Fe}^{3+} / \mathrm{UV} ; \mathbf{\Delta} \mathrm{Fecit} / \mathrm{UV} ; \bigcirc \mathrm{Fe}^{3+}$ $+0.10 \mathrm{mmol} \mathrm{L}{ }^{-1} \mathrm{CAT} /$ dark; $\mathrm{Fe}^{3+} /$ dark; $\mathrm{Fe}^{3+}+0.10 \mathrm{mmol} \mathrm{L}{ }^{-1} \mathrm{HQ} /$ dark 
Fig. 3 Proposed Fenton degradation pathway for PCT in the absence of HQ

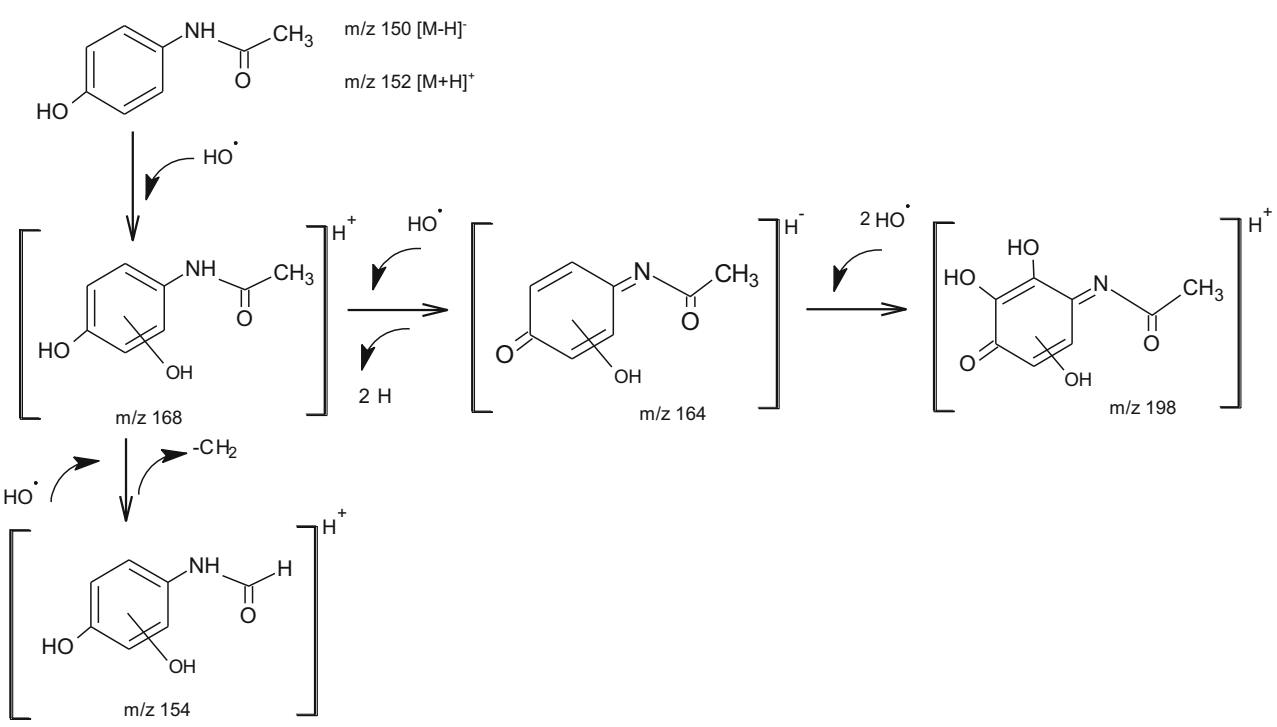

presence of $\mathrm{DHB}$, reduction of $\mathrm{Fe}^{3+}$ was immediate, generating stoichiometric amount of $\mathrm{Fe}^{2+}$. Irradiation of free iron and Fecit complex also lead to $\mathrm{Fe}$ (III) reduction, however, at much lower rate. When comparing citrate complex and free iron, higher rate of $\mathrm{Fe}^{2+}$ formation was observed in the presence of Fecit complex, but has reached a plateau due to degradation of citrate, while lower but continuous $\mathrm{Fe}$ (II) generation was observed with free iron. In the dark, although at much lower extent, Fe(III) reduction also occurred generating $0.021 \mathrm{mmol} \mathrm{L}^{-1} \mathrm{Fe}^{2+}$ (Fig. 2, green line), a different behavior as previously observed with phenol and $\mathrm{Fe}(\mathrm{III})$, when no $\mathrm{Fe}^{2+}$ was detected in the dark
(Silva and Nogueira 2016), suggesting that other dihydroxylated products generated during PCT degradation contributed to iron reduction.

\section{Degradation pathway of PCT during Fenton process}

LC-MS/MS analyses of PCT solution before degradation detected the pseudo-molecular ion of PCT with a mass to charge ratio $(\mathrm{m} / \mathrm{z}) 152\left([\mathrm{M}+\mathrm{H}]^{+}\right)($Fig. 3). MS/MS experiment of $\mathrm{m} / \mathrm{z}$ 152 detected fragment ions with $\mathrm{m} / \mathrm{z} 134$ and m/z 110 which correspond to water loss and ketone group loss $\left(-\mathrm{CH}_{2} \mathrm{CO}\right)$, respectively.
Fig. 4 Influence of HQ on (a) oxidation, (b) mineralization of $\mathrm{CIP}$, and (c) $\mathrm{H}_{2} \mathrm{O}_{2}$ consumption. Initial conditions:

$\mathrm{C}_{\mathrm{CIP}}=0.4 \mathrm{mmol} \mathrm{L}^{-1}$

$\mathrm{C}_{\mathrm{Fe} 3+}=0.1 \mathrm{mmol} \mathrm{L}^{-1}$

$\mathrm{C}_{\mathrm{H} 2 \mathrm{O} 2}=2.5 \mathrm{mmol} \mathrm{L}^{-1}$;

$\mathrm{C}_{\mathrm{HQ}}=0,1 \mathrm{mmol} \mathrm{L}^{-1} ; \mathrm{pH} 2.5$;

$\mathrm{Fe}^{3+} / \mathrm{UV} ; \mathrm{Fe}^{3+} /$ dark; $\mathrm{Fe}^{3+}+$ $0.10 \mathrm{mmol} \mathrm{L}^{-1} \mathrm{HQ} 0 \mathrm{~min} /$ dark; $\mathrm{Fe}^{3+}+0.10 \mathrm{mmol} \mathrm{L}^{-1} \mathrm{HQ}$

$30 \mathrm{~min} /$ dark a

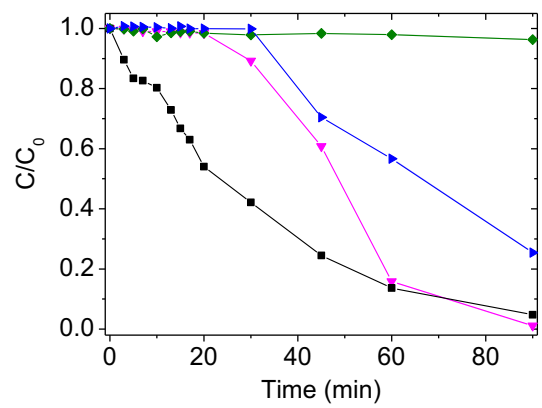

b

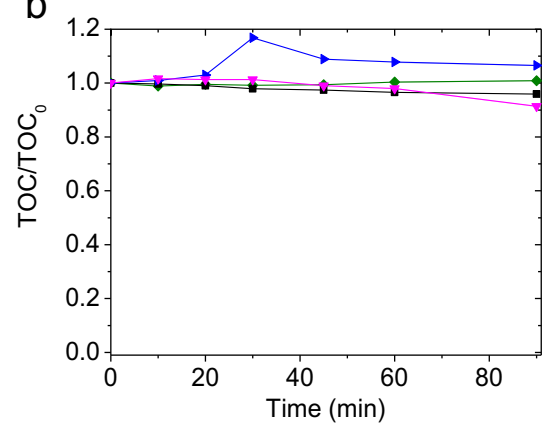

C

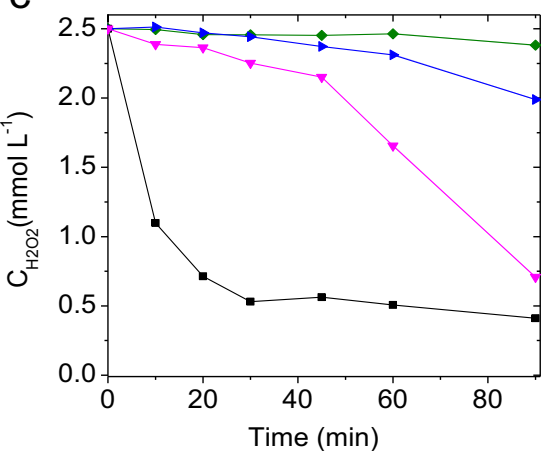




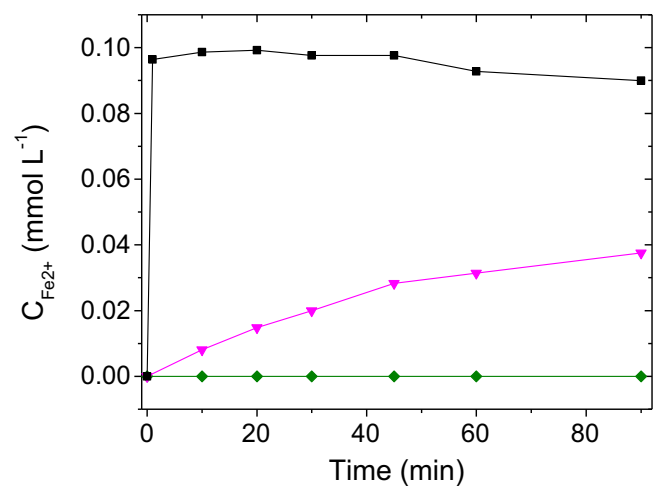

Fig. 5 Generation of Fe(II) during CIP degradation in the absence of $\mathrm{H}_{2} \mathrm{O}_{2}$ in the presence and absence of $\mathrm{HQ}$ in the dark and irradiation. Initial conditions: $\mathrm{C}_{\mathrm{CIP}}=0.4 \mathrm{mmol} \mathrm{L}^{-1} ; \mathrm{C}_{\mathrm{Fe} 3+}=0.1 \mathrm{mmol} \mathrm{L}^{-1} ; \mathrm{C}_{\mathrm{HO}}=0.1 \mathrm{mmol} \mathrm{L}^{-1}$; pH 2.5; $\diamond \mathrm{Fe}^{3+} /$ dark; $\nabla \mathrm{Fe}^{3+} / \mathrm{UV} ; \square \mathrm{Fe}^{3+}+0.10 \mathrm{mmol} \mathrm{L}{ }^{-1} \mathrm{HQ} 0$ min/dark

LC-MS/MS analysis during PCT degradation in the absence of HQ detected three isomers with $\mathrm{m} / \mathrm{z} 168\left([\mathrm{M}+\mathrm{H}]^{+}\right)$ with retention times 4.94, 6.41, and 6.80 min between 20 and 45 min reaction in the absence of HQ that correspond to products of hydroxyl radical attack on benzene ring on ortho and meta position and attack on amine group (Fig. 3). The MS/MS experiment of $\mathrm{m} / \mathrm{z} 168$ showed a main fragment with $\mathrm{m} / \mathrm{z} 126$, which corresponds to the loss of ketone $\left(-\mathrm{CH}_{2} \mathrm{CO}\right)$ (Fig. SM2). When HQ was added, they were detected only in the 5 -min sample due to the faster PCT degradation than in the absence of HQ. Two isomers with $\mathrm{m} / \mathrm{z} 168$ were previously reported in photo-Fenton degradation, $\mathrm{TiO}_{2}$ photocatalysis and ozonation under different PCT concentrations (Trovó et al. 2012; Moctezuma et al. 2012; Andreozzi et al. 2003).

Four isomers with $\mathrm{m} / \mathrm{z} 154\left([\mathrm{M}+\mathrm{H}]^{+}\right)$were detected at 4.49, 5.75, 7.45, and 10.09 min retention time after 20, 30, and 45 min reaction which are a product of $-\mathrm{CH}_{2}$ loss from intermediate $\mathrm{m} / \mathrm{z} 168$. The MS/MS experiments of $\mathrm{m} / \mathrm{z} 154$ showed the main fragments with $\mathrm{m} / \mathrm{z} 126$ which correspond to the loss of CO (Fig. SM3). Intermediate with $\mathrm{m} / \mathrm{z} 164$ ([M $-\mathrm{H}]^{-}$) is a product of two oxidation steps from $\mathrm{m} / \mathrm{z} 168$ which was detected after 30 and $45 \mathrm{~min}$ reaction. The MS/MS spectrum of $\mathrm{m} / \mathrm{z} 164$ showed a main fragment with $\mathrm{m} / \mathrm{z} 149$ which corresponds to the loss of methyl group $\left(-\mathrm{CH}_{3}\right)$. Two isomers with $\mathrm{m} / \mathrm{z} 198\left([\mathrm{M}+\mathrm{H}]^{+}\right)$were detected at 7.43 and $8.86 \mathrm{~min}$ retention time in the 5-min sample which correspond to the product of two hydroxylation steps from intermediate with $\mathrm{m} /$ z 164. The MS/MS experiments of $\mathrm{m} / \mathrm{z} 198$ showed a main fragment with $\mathrm{m} / \mathrm{z} 156$ formed from the loss of ketone group
$\left(-\mathrm{CH}_{2} \mathrm{CO}\right)$ (Fig. SM4). The fragments detected in MS/MS experiments confirmed the proposed structures.

\section{Effect of HQ on CIP degradation}

CIP was chosen for comparison with PCT because of the absence of phenolic group in its structure avoids the generation of DHB as initial degradation product. CIP degradation was also compared in the absence and presence of added HQ to evaluate its effect on CIP degradation.

No CIP degradation or $\mathrm{H}_{2} \mathrm{O}_{2}$ decomposition was observed in the dark in the presence of $\mathrm{Fe}^{3+}$ and absence of $\mathrm{HQ}$, note that CIP complexes $\mathrm{Fe}(\mathrm{III})$ forming $\mathrm{Fe}(\mathrm{CIP})_{2}$ and FeCIP (Eldin et al. 1996; Fratini and Schapoval 1996) (Fig. 5a). Under irradiation, CIP concentration started to decrease only after $20 \mathrm{~min}$, probably due to photodecomposition of $\mathrm{Fe}(\mathrm{CIP})$ complexes, reaching a degradation rate of $0.0055 \mathrm{mmol} \mathrm{L}^{-1} \mathrm{~min}^{-1}$, and contribution of irradiation on $\mathrm{Fe}^{2+}$ regeneration resulting in total CIP degradation after $90 \mathrm{~min}$. Addition of HQ in the dark ( $30 \mathrm{~min}$ ) increased the degradation rate drastically reaching $0.0056 \mathrm{mmol} \mathrm{L}^{-1} \mathrm{~min}^{-1}$ up to $90 \mathrm{~min}$. When HQ was added at the beginning of reaction, CIP degradation started with higher initial rate denoting the importance of HQ on degradation achieving $0.015 \mathrm{mmol} \mathrm{L}^{-1} \mathrm{~min}^{-1}$ after $20 \mathrm{~min}$ and over $95 \% \mathrm{CIP}$ degradation was observed at the end of experiment in the dark (Fig. 4a).

In relation to TOC removal, a similar behavior was observed under irradiation with $\mathrm{Fe}^{3+}$ and in the presence of $\mathrm{HQ}$ already at the beginning resulting in 9 and $4 \%$ removal, respectively, after $90 \mathrm{~min}$, while in the dark, no TOC removal was observed, and HQ addition after 30 min increased TOC values (Fig. 4b).

The $\mathrm{H}_{2} \mathrm{O}_{2}$ consumption showed a similar behavior when compared to CIP degradation showing a fast initial decomposition when HQ was added at the beginning of the reaction (56\% after $10 \mathrm{~min}$ ) (Fig. 4c). When HQ was added after $30 \mathrm{~min}, 20 \% \mathrm{H}_{2} \mathrm{O}_{2}$ was consumed after $90 \mathrm{~min}$. Irradiation increased $\mathrm{H}_{2} \mathrm{O}_{2}$ consumption (5.6\%) only slightly after 20 min than in the dark. Therefore, higher $\mathrm{H}_{2} \mathrm{O}_{2}$ consumption in the presence of $\mathrm{HQ}$ was observed than under irradiation and in the dark, due to the $\mathrm{Fe}^{2+}$ generation.

The $\mathrm{Fe}^{2+}$ generated during CIP degradation in the presence of HQ in the dark (absence of $\mathrm{H}_{2} \mathrm{O}_{2}$ ) showed similar results as for PCT, with total reduction in a very short time (Fig. 5). Irradiation also leads to $\mathrm{Fe}(\mathrm{III})$ reduction, however, at much
Fig. 6 Proposed CIP degradation pathway with the addition of HQ

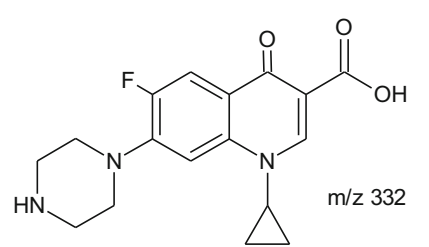

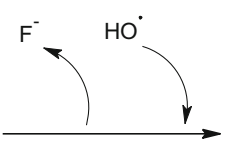<smiles>O=C(O)c1cn(C2CC2)c2cc(N3CCNCC3)c(O)cc2c1=O</smiles> 
lower rate than in the presence of HQ achieving $0.038 \mathrm{mmol} \mathrm{L}^{-1}$ only after $90 \mathrm{~min}$, while no reduction was observed in the dark probably due to no generation of dihydroxylated intermediate which could contribute on Fe(III) reduction.

\section{Degradation pathway of CIP during Fenton process}

LC-MS/MS analysis of CIP detected the pseudo-molecular ion of CIP $\mathrm{m} / \mathrm{z} 332\left([\mathrm{M}+\mathrm{H}]^{+}\right)$. MS/MS experiment of $\mathrm{m} / \mathrm{z}$ 332 detected fragment ions $\mathrm{m} / \mathrm{z} 314, \mathrm{~m} / \mathrm{z} 288, \mathrm{~m} / \mathrm{z} 245$, and $\mathrm{m} / \mathrm{z} 231$ which corresponds to water and carboxyl group loss $\left(\mathrm{COO}^{-}\right)$, piperazine cleavage, and cyclopropyl ring elimination, respectively.

LC-MS/MS analysis during CIP degradation detected one main intermediate compound up to 30 min reaction (Fig. 6). The intermediate with $\mathrm{m} / \mathrm{z} 330[\mathrm{M}+\mathrm{H}]^{+}$was formed after hydroxyl radical attack on benzene ring in an electrophilic addition reaction and consequent release of fluoride as previously observed in photo-Fenton degradation of ofloxacin and CIP with fluoride quantification in solution (Michael et al. 2013; Perini et al. 2014). The MS/MS experiments of $\mathrm{m} / \mathrm{z}$ 330 showed the main fragments $\mathrm{m} / \mathrm{z} 312$ and $\mathrm{m} / \mathrm{z} 286$ which correspond to the loss of water and of $\mathrm{COO}^{-}$, respectively, confirming the structure of this intermediate (Fig. SM5). Although a further hydroxylation could be feasible, no dihydroxylated product was detected under the conditions of this work.

\section{Conclusions}

The results of this work demonstrate that PCT degradation in the dark is strongly affected by the generation of HQ and other hydroxylated degradation products, changing drastically degradation kinetics due to their contribution on iron cycling, reduction of $\mathrm{Fe}^{3+}$ to $\mathrm{Fe}^{2+}$. However, no similar contribution was observed in the case of CIP, without degradation or iron reduction in the dark. CIP degradation in the dark was only observed after the addition of HQ, which increased significantly both PCT and CIP degradation rate. Irradiation favored degradation of both pharmaceuticals, however, at lower extent when compared to the addition of DHB.

Ten di- and tri-hydroxylated PCT degradation products were identified in the absence of HQ resulting from hydroxyl radical attack on benzene ring and amine group, which contributed on iron reduction and consequently PCT degradation. One CIP degradation product resulting from hydroxyl radical attack on benzene ring and substitution of the fluorine atom was identified, however, without showing a contribution on its degradation.
Acknowledgments The authors thank CNPq for the support of this work (Process 308358/2011-2) and scholarship awarded to J. A. L. Perini (Process 151022/2014-3) and CAPES for the scholarship awarded to B. C. e Silva. The authors also thank B. F da Silva for LC-MS/MS analysis.

\section{References}

Abrahamson HB, Rezvani AB, Brushmiller JG (1994) Photochemical and spectroscopic studies of complexes of iron(III) with citric acid and other carboxylic acids. Inorg Chim Acta 226:117-127. doi:10. 1016/0020-1693(94)04077-X

Aguiar A, Ferraz A, Contreras D (2007) $\mathrm{Fe}^{3+}$ - and $\mathrm{Cu}^{2+}$ - reduction by phenol derivatives associated with Azure B degradation in Fentonlike reactions. Quim Nov. 66:947-954. doi:10.1016/j.chemosphere. 2006.05.067

Andreozzi R, Caprio V, Marotta R, Vogna D (2003) Paracetamol oxidation from aqueous solutions by means of ozonation and $\mathrm{H}_{2} \mathrm{O}_{2} / \mathrm{UV}$ system. Water Res 37:993-1004. doi:10.1016/S0043-1354(02) 00460-8

Chen R, Pignatello JJ (1997) Role of quinone intermediates as electron shuttles in Fenton and photoassisted Fenton oxidations of aromatic. Environ Sci Technol 31:2399-2406

Chen F, Ma W, He J, Zhao J (2002) Fenton degradation of malachite green catalyzed by aromatic additives. J Phys Chem 106:94859490. doi:10.1021/jp0144350

Devi LG, Rajashekhar KE, Raju KSA, Kumar SG (2011) Influence of various aromatic derivatives on the advanced photo Fenton degradation of Amaranth dye. Desalination 270:31-39. doi:10.1016/j. desal.2010.11.017

Eldin F, Suliman O, Sultan SM (1996) Talanta 43:559-568. doi:10.1016/ 0039-9140(95)01771-2

Fortune WB, Mellon MG (1938) Determination of Iron with ophenanthroline: a spectrophotometric study. Ind Eng Chem Anal Ed 10:60-64. doi:10.1021/ac50118a004

Fratini L, Schapoval EES (1996) Ciprofloxacin determination by visible light spectrophotometry using iron (III) nitrate. Int J Pharm 127: 279-282. doi:10.1016/0378-5173(95)04290-3

Haddou M, Benoit-Marquié F, Maurette M, Oliveros E (2010) Oxidative degradation of 2,4-dihydroxybenzoic acid by Fenton and photoFenton process: kinetics, mechanisms, and evidence for the substitution of $\mathrm{H}_{2} \mathrm{O}_{2}$ by $\mathrm{O}_{2}$. Helv Chim Acta 93:1067-1080. doi:10.1002/ hlca. 200900380

Laurentiis E, Prasse C, Ternes TA, Minella M, Maurino V, Minero C, Sarakha M, Brigante M, Vione D (2014) Assessing the photochemical transformation pathways of acetaminophen relevant to surface waters: transformation kinetics, intermediates, and modelling. Water Res 53:235-248. doi:10.1016/j.watres.2014.01.016

Malato S, Blanco J, Cáceres J, Fernandez-Alba AR, Agüera A, Rodriguez A (2002) Photocatalytic treatment of water-soluble pesticides by photo-Fenton and $\mathrm{TiO}_{2}$ using solar energy. Catal Today 76:209220. doi:10.1016/S0920-5861(02)00220-1

Michael I, Hapeshi E, Aceña J, Perez S, Petrović M, Zapata A, Barceló D, Malato S, Fatta-Kassino D (2013) Light-induced catalytic transformation of ofloxacin by solar Fenton in various water matrices at a pilot plant: mineralization and characterization of major intermediate products. Sci Total Environ 461:39-48. doi:10.1016/j.scitotenv. 2013.04.054

Minella M, Marchetti G, Laurentiis E, Malandrino M, Maurino V, Minero C, Vione D, Hanna K (2014) Photo-Fenton oxidation of phenol with magnetite as iron source. Appl Catal B 154-155:102-109. doi:10. 1016/j.apcatb.2014.02.006 
Minero C, Lucchiari M, Maurino V, Vione D (2013) A quantitative assessment of the production of ${ }^{\circ} \mathrm{OH}$ and additional oxidants in the dark Fenton reaction: Fenton degradation of aromatic amines. RSC Adv 3:26443-26450. doi:10.1039/c3ra44585b

Moctezuma E, Leyva E, Aguilar CA, Luna RA, Montalvo C (2012) Photocatalytic degradation of paracetamol: intermediates and total reaction mechanism. J Hazard Mater 243:130-138. doi:10.1016/j. jhazmat.2012.10.010

Nichela D, Haddou M, Benoit-Marquié F, Maurtte MT, Oliveros E, García Eischlag FS (2010) Degradation kinetics of hydroxy and hydroxynitro derivatives of benzoic acid by fenton-like and photofenton techniques: a comparative study. Appl Catal B-Environ 98: 171-179. doi:10.1016/j.apcatb.2010.05.026

Nogueira RFP, Guimarães JR (2000) Photodegradation of dichloroacetic acid and 2,4-dichlorophenol by ferrioxalate/ $\mathrm{H} 2 \mathrm{O} 2$ system. Water Res 34:895-901. doi:10.1016/S0043-1354(99)00193-1

Nogueira RFP, Silva MRA, Trovó AG (2005a) Influence of the iron source on the solar photo-Fenton degradation of different classes of organic compounds. Sol Energy 79:384-392. doi:10.1016/j. solener.2005.02.019

Nogueira RFP, Oliveira MC, Paterlini WC (2005b) Simple and fast spectrophotometric determination of $\mathrm{H}_{2} \mathrm{O}_{2}$ in photo-Fenton reactions using metavanadate. Talanta 66:86-91. doi:10.1016/j.talanta.2004. 10.001

Pang S-Y, Jiang J, Ma J (2011) Oxidation of sulfoxides and arsenic (III) in corrosion of nanoscale zero valent iron by oxygen: evidence against ferryl ions $(\mathrm{Fe}(\mathrm{IV}))$ as active intermediates in Fenton reaction. Environ Sci Technol 45:307-312. doi:10.1021/es102401d

Perini JAL, Silva BF, Nogueira RFP (2014) Zero-valent iron mediated degradation of ciprofloxacin - assessment of adsorption, operational parameters and degradation products. Chemosphere 117:345-352. doi:10.1016/j.chemosphere.2014.07.071
Pignatello JJ (1992) Dark and photoassisted $\mathrm{Fe}^{3+}$-catalyzed degradation of chlorophenoxy herbicides by hydrogen peroxide. Environ Sci Technol 26:944-951. doi:10.1021/es00029a012

Pignatello JJ, Oliveros E, Mackay A (2006) Advanced oxidation processes for organic contaminant destruction based on the Fenton reaction and related chemistry. Crit Rev Environ Sci Technol 36:1-84. doi: 10.1080/10643380500326564

Pomati F, Castiglioni S, Zuccato E, Fanelli R, Vigetti D, Rossetti C, Calamari D (2006) Effects of a complex mixture of therapeutic drugs at environmental levels on human embryonic cells. Environ Sci Technol 40:2442-2447. doi:10.1021/es051715a

Rúa-Gómez CP, Püttmann W (2013) Degradation of lidocaine, tramadol, venlafaxine and the metabolites O-desmethyltramadol and $\mathrm{O}$ desmethylvenlafaxine in surface waters. Chemosphere 90:19521959. doi:10.1016/j.chemosphere.2012.10.039

Safarzadeh-Amiri A, Bolton JR, Cater SR (1996) Ferrioxalate-mediated solar degradation of organic contaminants in water. Sol Energy 56: 439-443. doi:10.1016/0038-092X(96)00002-3

Silva BC, Nogueira RFP (2016) Contribution of irradiation and dihydroxybenzenes on iron (III) reduction in Fenton process. J Bras Chem Soc in press

Trovó AG, Nogueira RFP, Agüera A, Fernandez-Alba AR, Malato S (2012) Paracetamol degradation intermediates and toxicity during photo-Fenton treatment using different iron species. Water Res 46: 5374-5380. doi:10.1016/j.watres.2012.07.015

Wang JL, Xu LJ (2012) Advanced oxidation processes for wastewater treatment: formation of hydroxyl radical and application. Environ Sci Technol 42:251-325. doi:10.1080/10643389.2010.507698

Wang L, Zhang C, Mestankova H, Wu F, Deng N, Pan G, Bolte M, Mailhot G (2009) Photochem Photobiol Sci 8:1059-1065. doi:10. 1039/b902607j 